\title{
Lloren las ranas, casen las aguas, conténganse los vientos. Rituales para llamar la lluvia en el centro y sur andino
}

\author{
Francisco M. GIL GARCíA \\ Universidad Complutense de Madrid (España) \\ Dpto. de Historia de América II (Antropología de América) \\ fmgilgar@ghis.ucm.es
}

Recibido: 5 de septiembre de 2011

Aceptado: 27 de septiembre de 2011

\section{RESUMEN}

Este trabajo presenta un estudio bibliográfico y plantea un estado de la cuestión sobre los rituales para llamar la lluvia en el centro y sur andino, tratando de sintetizar puntos comunes dentro de sus múltiples variables. Para ello se presta especial atención a las instancias de invocación por un lado y a las ofrendas por otro, sin perder de vista el proceder de los ritualistas a la hora de hacer llegar las segundas a las primeras.

Palabras clave: Rituales para llamar la lluvia, espacios ceremoniales, agua, lagos y lagunas, cerros, ofrendas.

\section{Cry the Frogs, Marry the Waters, Stop the Winds. Rituals For Attract Rain in Central and Southern Andes}

\begin{abstract}
This paper presents a literature review and the state of the question on rituals to call the rain in central and southern Andes, due to synthesize commonalities within their multiple variables. I pay particular attention to instances of invocation, offerings, and the conduct of ritualistas (ritual specialists).
\end{abstract}

Key words: rituals to call the rain, ceremonial spaces, water, lakes and ponds, mountains, offerings

Sumario: 1. Introducción. 2. Cerros y lagunas. 3. Misericordia Señor, misericordia. 4. Llamando lluvia a cántaros. 5. Agitando las aguas, molestando a la laguna. 6. El casamiento de todas las aguas. 7. Conteniendo a los vientos. 8. La lluvia y los ancestros. 9. Mesas blancas, mesas negras y otros pagos. 10. Consideraciones finales. 11. Referencias bibliográficas.

\section{Introducción}

Cuentan que Pachacámac y Viracocha ordenaron el Mundo y situaron en los cielos a una hermosa doncella dándole un cántaro de agua para derramarla sobre la tierra cada vez que ésta la necesitara; cuando la lluvia cae apaciblemente es porque la doncella está vertiendo su cántaro sin que nadie la moleste, pero si lo hace envuelta en tempestades es porque su fastidioso hermano, el Rayo, le ha roto el cántaro para hacerle rabiar (Oliveira 2007: 60-61). Agua de lluvia: elemento fundamental en el porvenir de las comunidades agropastoriles de los Andes, fuente de vida de la cual 
dependen la fertilidad de las cosechas y la reproducción de los ganados, y por ende la supervivencia humana. Por eso sus gentes se empeñan en rendir culto a las entidades tutelares que la controlan: además de la legendaria doncella - de la que en la literatura etnográfica no he encontrado mención alguna, dicho sea de paso--, el Rayo, la Pachamama, los cerros, lagos y lagunas, los vientos, incluso los difuntos y algunos santos y vírgenes dentro del catolicismo popular, a todos ellos se les rinde culto para conjurar la sequía, para que llueva, pero para «que llueva bien», a tiempo, para que siga lloviendo, y hasta para que deje de llover si es que estuviera lloviendo «mal». Aún si hoy llueve se les dispensa atención, por si mañana escampase cuando la lluvia todavía fuera necesaria. A este tipo de prácticas rituales es a las que se da el nombre genérico de llamados de lluvia.

En tanto que ritos de reciprocidad, los llamados de lluvia implican ceremoniales y ofrendas complejos. A lo largo y ancho del mundo andino su casuística resulta de lo más variopinta, pero a pesar de las particularidades del rito desarrollado por cada comunidad concreta es posible aislar ciertos elementos comunes a todos ellos, elementos que tienen que ver fundamentalmente con las instancias de invocación, las ofrendas, el proceder de los especialistas rituales y las oraciones o plegarias. Dedicaré las páginas siguientes a la composición de una síntesis etnográfica de estos puntos comunes ${ }^{1}$, atendiendo sobre todo a los tres primeros y marginando el análisis de los rezos por una cuestión de espacio pero sobre todo por la llamativa ausencia de su registro en la literatura etnográfica especializada. Más allá de menciones a que rezan a tal o cual entidad, piden esto o aquello, utilizan un tono u otro, no se prodiga en las etnografías sobre llamados de lluvia el análisis de las oraciones, y a veces ni siquiera su trascripción/traducción (vid Rösing 1996 como notable excepción en ambos sentidos). Pero quizás el problema de base sea que no abundan las etnografías de llamados de lluvia.

Insertos en lo que podrían denominarse ritos o fiestas del agua, los llamados de lluvia han sido mucho menos estudiados que otras prácticas, como por ejemplo la limpieza de canales o el reparto de aguas de riego, a pesar del consenso en afirmar que las creencias y los ritos ligados al agua, y en particular a la lluvia, son los que mejor sobrevivieron a la extirpación de idolatrías durante la Colonia y más «típicamente indígenas» han llegado hasta nuestros días (Gelles 1986: 117; Greslou 1990; Rösing 1996: 104)². Dicho vacío se ha justificado generalmente desde su consideración como

\footnotetext{
1 Huelga indicar que resulta imposible hacer un vaciado de la bibliografía existente sobre el tema en las páginas que ocupa este artículo, algo que que, por otra parte, nunca constituyó mi objetivo para este trabajo. Lo que pretendo más bien -tal y como indico- es identificar dichos elementos comunes y ordenar unas categorías tipológicas desde las cuales poder abordar el análisis de los llamados de lluvia. Para un completo estudio crítico de la literatura etnográfica relativa a los llamados de lluvia remito al lector interesado al trabajo de Rösing (1996), más centrado en los Andes bolivianos, así como a la tabla de referencia compuesta por Van der Berg (1989: 247-248) y completada por la propia Rösing (1996: 107-108).

2 Como siempre en estos casos, la pregunta de rigor es cuánto de prehispánico sigue vigente en los cultos actuales y en qué grado de transformación, pues si bien es cierto que las instancias de invocación para que llueva y el significado simbólico de las ofrendas a ellas despachadas se han mantenido por lo general bastante alejadas del sincretismo religioso, también lo es que el catolicismo popular andino se ha colado en los llamados de lluvia, como habrá ocasión de ir presentando. Con todo, yo mismo «pecaré» de citar algunos testimonios de los siglos XVI-XVII cuando la comparación resulte oportuna y «justifique» una correlación directa con los ritos $\mathrm{y} / \mathrm{o}$ las creencias actuales.
} 
ritos coyunturales, algo que es tan sólo en parte cierto. Efectivamente, en muchos casos se llamará a la lluvia exclusivamente cuando sea necesario contrarrestar una pertinaz sequía. En un año normal, las lluvias empezarían a caer en noviembre, pero si septiembre, octubre y noviembre han sido meses muy secos y en diciembre todavía no ha llovido, será entonces cuando se proceda a llamar a la lluvia. Esta eventualidad complica el desarrollo de un trabajo de campo planificado con antelación, que queda así a merced de las condiciones meteorológicas del año y sobre todo de la casualidad de que el investigador se encuentre en el lugar adecuado en el momento oportuno. Pero también pueden ser ritos programados dentro del ciclo anual, quizás el único rito anual que celebra la comunidad (p.ej. en la comunidad kallawaya de Niñokorin, donde, aunque ya esté lloviendo, no dejan de celebrar todos los meses de diciembre su particular llamado de lluvia, el Tarpuy Qallay [Rösing 1996: 350-353]), y más aún el único costumbre que celebran comunidades muy mestizadas y con evidente pérdida de tradiciones (p.ej. las comunidades kallawayas del altiplano boliviano de Chucuipo o Jatichulaya [Rösing 1996: 353-357]), o con fuerte y constrictora presencia evangélica (p.ej. la comunidad aymara de Upinhuaya, en el altiplano de La Paz, Bolivia [Rösing 1996: 358-366]). Ritos que entonces tendrán lugar durante el mes de noviembre, pasada la festividad de Todos los Santos, o a primeros de diciembre a más tardar. Incluso podríamos encontrar comunidades que celebran un llamado de lluvia cíclico complementado o reforzado con ritos específicos de tipo coyuntural (p.ej. Chari, en la región kallawaya, con un rito anual en la segunda semana de septiembre que, de no surtir efecto más o menos inmediato, puede verse reforzado con ritos específicos hasta diciembre [Llanos 2004]).

Pero además se da el caso -y esto sí que dificulta su reconocimiento y análisis, al tiempo que los silencia en los buscadores de bases de datos- de que muchos llamados de lluvia han quedado absorbidos y hasta diluidos dentro de rituales vinculados al tiempo de siembra, durante los meses de febrero y marzo (p.ej. en el valle del Colca, Perú [Valderrama y Escalante 1988]); o a la limpieza de canales y el «despertar» de los sembradíos en primavera (p.ej. en Puquio -Ayacucho, Perú- [Valiente 1986] o también en diferentes comunidades atacameñas de Antofagasta, Chile [Barthel 1986]); o al traspaso de poderes entre «alcaldes de aguas» (Gelles 2002; Sikkink 1997; Valderrama y Escalante 1988); o al reparto de aguas de riego bien entre comunidades, bien entre vecinos (Gerbrandy y Hoogendam 1998); o a grandes rituales comunitarios anuales destinados a la resolución de conflictos, la aplicación de reconocimientos y castigos, el control simbólico del agua y del poder político, y/o a la propiciación de prosperidad para el pueblo (p.ej. en Casta -Huarochirí, Perú- [Gelles 1996]). Y hasta puede que los llamados de lluvia se desliguen del conjunto de ritos agrícolas y pasen a ser abordados desde la perspectiva del mundo mágico y la medicina tradicional como un tipo de «magia pluvial» (Polia Meconi 1988: 89-96).

Con este panorama, no es de extrañar que entre los llamadores de lluvia mencionados en la literatura etnográfica aparezcan especialistas rituales de diferente condición y estatus, maestros de ceremonias (aparentemente no especialistas rituales), alcaldes, regidores, síndicos, distintos escalafones en el sistema de cargos (cívico y/o ritual) de las comunidades, y hacedores de lluvia. Llamadores versus hacedores de lluvia es una distinción que va más allá del juego de palabras -inspirada en el trabajo de 
Antúnez (1986) sobre el riego en Aija (Ancash, Perú) - y que tiene que ver con la idea de que los primeros llaman a la lluvia mediante rezos, ofrendas o «magias», mientras que los segundos la fabrican mediante técnicas de control climático por medio de las cuales se altera la meteorología local y se logra generar nubes pluviales. Sin embargo, por operatividad de conceptos en este artículo de síntesis, prefiero reservar estas diferenciaciones de matiz para otro trabajo específico y considerar aquí a todos bajo el rubro neutro de ritualistas ${ }^{3}$ u oficiantes en los ritos para llamar la lluvia.

Sea como fuere, y al margen de distinciones entre ritualistas y sus procederes, la base de los llamados de lluvia queda anclada dentro de una visión cósmica de la circulación del agua: de los cerros y lagunas, a los manantiales, a los canales de riego, a los campos, o directamente al mar... ahí se evapora y se convierte en agua contenida en nubes pluviales que nuevamente habrán de descargar su agua; todo ello organizado en torno a una concepción cíclica del tiempo que diferencia claramente entre la época de secas y la época de lluvias. Por eso, los hombres enfrentan la sequía como un desorden a combatir, a remediar, manipulando la Naturaleza a través del rito para lograr que este equilibrio fundamental se restituya. En este sentido -tengámoslo bien presente a la hora de entender el sentido y la lógica de los llamados de lluvia-, hacer lo imposible por atraer a la lluvia no se entiende como una forma de oponerse a la Naturaleza, sino más bien de mantener dicho equilibrio roto por diferentes causas, naturales o sobrenaturales (v.gr. Llanos 2004: 163; Valderrama y Escalante 1988: 104-105; Van der Berg 1980).

\section{Cerros y lagunas}

Si antes señalé diversas instancias de invocación en los rituales para llamar la lluvia, lo cierto es que todas ellas quedan concentradas en torno a dos escenarios ceremoniales fundamentales, que se vuelven asimismo en instancias de invocación de primer orden: los cerros y las lagunas, constructores del espacio simbólico de las alturas. Ahora bien, no cualquier cerro y tampoco cualquier laguna. Lógicamente, cada comunidad se sitúa a la sombra de sus cerros tutelares y es a ellos a los que recurre a la hora de pedir agua de lluvia, porque en ellos habitan las «divinidades», el Rayo (Illapa/Santiago), los vientos, los antepasados, o por el mero hecho de que las altas cumbres de la cordillera andina suelen estar coronadas de nubes; a los cerros se presupone el poder sobre las nubes y en particular sobre las nubes pluviales. Cerros propios pero también cerros ajenos que son apropiados como parte de los paisajes rituales ora de las comunidades, ora de los especialistas rituales que ofician el llamado de lluvia. En ocasiones -señala Vellard (1981: 170)-, estas grandes cumbres (Sajama, Illimani, Illampu, Huayna Potosí, Mururata, entre otras), antropomorfizadas y divinizadas, se

\footnotetext{
3 Bajo la denominación de ritualistas se engloban todos aquellos especialistas rituales, sabios, curanderos, brujos, chamanes, etc., que bien como consecuencia de un don y/o tras haber superado un período de iniciación y formación, son capaces de sanar enfermedades, adivinar, invocar a los espíritus, entrar en contacto con las entidades tutelares, etc., y a los que se suele encomendar la tarea de oficiar los ritos. Quedan así diferenciados de otros oficiantes que, en virtud de su estatus dentro de la comunidad, por estar desempeñando un cargo o por patrocinar una celebración o un ritual, pudieran desempeñar tareas puntuales en un rito determinado.
} 
comportan como chiquillos que juegan entre sí pasándose las nubes que soplan los vientos. Por eso en el día de San Andrés, patrón de los vientos, los ritualistas eligen a su favorito y apuestan por él, rogándole al mismo tiempo que cuando logre quedarse con las nubes las lleve sobre sus comunidades.

Algo similar creen los kallawayas de Khata (La Paz, Bolivia) que ocurre con los lagos. El más importante dentro de su entorno regional es el Pachacota, pero a veces otros le toman la mano y se hacen con el control de las nubes pluviales. Por eso el ritualista, previo al llamado de lluvia, debe leer la hoja de coca para averiguar a qué lago debe apelar, cuál es el «poseedor de la lluvia» en ese momento (Rösing 1996: 343-344).

Protagonistas de primer orden en la construcción de los paisajes simbólicos de las alturas, cerros y lagunas suelen actuar de la mano, ya sea porque para acceder a las lagunas es necesario ascender los cerros, ya porque las aguas del cerro y las de las lagunas deban «casarse» para reforzar la efectividad del rito. Pensando en términos duales, el cerro es masculino, y tanto el agua en general como la lluvia en particular son femeninos. Y digo en términos generales porque en esos paisajes sagrados, definidos a partir de entornos lacustres, es frecuente distinguir entre lagos/lagunas masculinos y femeninos. Lo mismo ocurre en el caso de los manantiales de los cerros: interpretadas como la sangre o el semen de estos, representarán indefectiblemente lo masculino, mientras que conceptualizadas como las esposas/amantes de estos remitirán a lo femenino ( $v$.gr . Valderrama y Escalante 1988 para el caso de los nevados Mismi y Waranqate, en el valle del Colca, Perú); incluso puede ser que entre los manantiales de un mismo cerro se distinga entre masculinas y femeninas, buscando el llamado de lluvia casar a las distintas aguas, dando así al rito una dimensión sexual y procreadora que, a través de la lluvia, engendre vida en sembradíos campos y pastos, como comentaré más adelante.

Originada entonces en cerros y lagunas, el agua de lluvia es agua de las alturas, y por tanto resulta investida de «poderes» a la hora de movilizar a los elementos de la Naturaleza; un agua, en suma, peligrosa si no sabe identificarse y manejarse bien. Así, Van der Berg (1989: 70, citando informes de campo inéditos de X. Albó para los años 1971-1974) recoge que en Corpa (Ingavi, La Paz, Bolivia) distinguen tres tipos de agua de las cumbres: una de lluvia (la más dulce), otra de nevada (la más salada) y otra de granizo (llamada "agua mineral»), y que hay que tener cuidado de no equivocarse al recogerla si no queremos obtener efectos nefastos no deseados. Algo similar señala Tillmann (1997: 107-108) para el caso de las lagunas de Tamias, en el valle oriental del Mantaro (Jauja, Perú): una de lluvia (femenina), otra de granizo (masculina), y otra -la más perjudicial- del Rayo (masculina), generalmente ocultas entre brumas, por lo que el ritualista deberá ser capaz de reconocerlas perfectamente para no equivocarse y desatar tempestades en vez de lluvias propicias.

Pero no sólo opera sobre el paisaje esta división masculino/femenino, sino en ocasiones también sobre los especialistas rituales. Así por ejemplo, Rösing (1996: 361363) señala cómo en algunas comunidades kayawallas del altiplano de La Paz (Bolivia), y de manera muy notable en la vecina comunidad aymara de Upinhuaya, los ritualistas se dividen entre los que pertenecen al ámbito de lo masculino (ligado a los cerros y el Rayo) y los que pertenecen al ámbito de lo femenino (todo lo relacionado 
con el agua, incluida la lluvia). De los primeros se dice que tienen «manos de calor», y por eso nunca serán requeridos para oficiar llamados de lluvia, pues más bien atraerían la sequía, todo lo contrario que los segundos, de quienes se dice específicamente que tienen «manos de lluvia».

Pero volvamos a las estrechas relaciones fraguadas entre cerros y lagunas a la hora de propiciar la lluvia. A este respecto, Vellard (1981: 172) señala que en los cantones meridionales del Titicaca, en torno al Kaphia o Monte Cólera, cuando la sequía se torna especialmente pertinaz, ritualistas y delegados de las comunidades afectadas ascienden con ofendas hasta la laguna (encantada) de Wara-Warani, de la que toman agua. De vuelta a sus pueblos ésta será mezclada con vino y pródigamente sahumada antes de emprender un circuito procesional que les lleve a regar con la mezcla la cima de los cerros más destacados del entorno. Una costumbre ésta de procesionar por los cerros para atraer la lluvia que parece se continúa desde época prehispánica. Poma de Ayala, por ejemplo, informa de que en el tiempo de los Incas, tanto en octubre (Uma Raymi Quilla, mes de la festividad del agua) como en noviembre (Aya Marcay Quilla, mes de llevar difuntos), y siempre que la sequía se prolongara fuera de su tiempo, se realizaban procesiones y penitencias de cerro en cerro marcadas por el luto, el llanto, los gritos desgarrados y la imploración de misericordia a Runa Camac (Creador del hombre) y a Pacha Camac (Creador del Universo) (1987 [1615]: 246, 1236-1237, 182-183 [ff. 255 (257), 1161 (1171), 190-191 (192-193)]). Asimismo, Antonio de la Calancha da cuenta de procesiones por los cerros y del poder de éstos a la hora de atraer la lluvia, al referir diferentes episodios de extirpación de la idolatría en el Perú de principios del siglo XVII, de cómo en 1596 tuvo lugar un movimiento mesiánico en Piti y Mara (provincia de Cotabambas) protagonizado por un indio que, diciéndose «lugarteniente de Dios pero actuando cual otro Anticristo», apartaba a los indios de su doctrina echando la culpa de una peste de sarampión y viruela al hecho de que los naturales estaban abrazando la fe de los cristianos. Hacedor de prodigios, este personaje «enseñado de espíritu maligno», era capaz de hacer temblar la tierra, de nublar o aclarar los cielos a su antojo, de agitar tempestades y sosegar los aires, de hacer nevar, así como -y éste es el punto que aquí nos interesa- de hacer llover, todo ello desde lo alto de un cerro próximo a estos dos pueblos (?) e investido del poder que la montaña le había transferido (Calancha y Torres 1972-I: 713).

Caso paradigmático de la relación entre cerros y lagunas a la hora de atraer la lluvia $-\mathrm{y}$ al mismo tiempo claro indicador de lo difícil que es identificar a veces en la literatura etnográfica los llamados de lluvia- podría ser la Fiesta del Agua en Puquio (Ayacucho, Perú) descrita por Valiente (1986: especialmente 90-95). A pesar de que la autora identifica ésta como una «fiesta del agua», un rito de fertilidad directamente relacionado con el ciclo agrícola y en particular con la limpieza de canales, se trata en realidad de un llamado de lluvia, un ritual con dos fases, dos destinatarios y dos escenarios diferenciados, pero marcados por el protagonismo de tres lagunas: en primer lugar, el pagapu o pago al cerro Pedrorko, a través de la laguna Qoricocha, y seguidamente, el angosay o pago a la Pachamama, en las lagunas Moyalla y Churulla. Sólo los ritualistas suben al cerro hasta el borde de la laguna. A medianoche depositan «los productos seleccionados»-que la autora no especifica- en un pukullo (tumba antigua, de los gentiles) y sacrifican al Pedrorko un carnero y una llama blanca, cuyos 
corazones son arrojados a las aguas. Después de este pago y del «abrazo ritual a una piedra determinada» (?), los ritualistas se duermen. Al amanecer desayunan parte de los animales sacrificados y, antes de emprender la bajada, recogen de la orilla de Qoricocha flores silvestres e ichu, con lo que confeccionan una cruz. Durante el descenso efectúan tres paradas en las que piden permiso al cerro para retirarse y anuncian a la Pachamama el pago que van a entregarle. Ese mismo día, toda la comunidad acude a la laguna Moyalla. Los ritualistas, situados a lo largo de la orilla, rezan a las cruces de paja y flores y también lo hacen las autoridades civiles. Se extrae agua de la laguna, que después de mezclarla con vino es devuelta a ella. Finalizado el ritual se impone la fiesta, con un banquete comunitario, música y bailes. Al día siguiente se repite la misma operación en la laguna Churulla. Varios de estos procederes volveremos a verlos en otros ejemplo, pero vayamos por partes.

\section{Misericordia Señor, misericordia}

Como en toda petición a instancias superiores de poder que se precie, los llamados de lluvia incluyen siempre, de modo más o menos visible y enfatizado, una súplica, y ésta a su vez sus correspondientes notas de lástima y solicitud de clemencia y misericordia. En este sentido, se puede apelar a la misericordia de los dueños de la lluvia a través del arrepentimiento comunitario, rogativas y procesiones de diferente signo o incluso recurriendo al maltrato de animales o niños con el fin de despertar la clemencia de la Naturaleza o de determinadas instancias de advocación, e incluso recurrir al maltrato a los santos católicos y hasta a la Pachamama.

Son peticiones de misericordia pero al mismo tiempo de perdón, pues el castigo divino o de la Naturaleza ocupa un lugar destacado entre las causas subjetivas para la sequía: una reacción al comportamiento anormal de los miembros de una misma familia, comunidad o región. Así lo registra, por ejemplo, Tillmann (1997: 92-102, 103, 112) en su trabajo de campo entre comunidades campesinas de Jauja (Perú); entre los «pecados» más frecuentes que le refieren sus informantes a la hora de interpretar la ausencia o el retraso de las lluvias: incesto, amancebamiento, adulterio, violencia doméstica, muertes violentas ${ }^{4}$ o pérdida de respeto hacia las autoridades tradicionales, ocupan un lugar destacado. Por su parte, Oblitas Poblete (1978: 179-184) comenta cómo, en época de sequía prolongada, los kallawayas ascienden al cráter del volcán Tuana -en cuya laguna ubican el palacio de Mama Para y sus hermanos Rayo y Trueno- para apelar a su clemencia y obtener el perdón por las faltas que cualquiera de ellos hubiera podido cometer y a cuenta de las cuales están siendo castigados con falta de lluvias. Todo ello acompañado de un ritual y unas ofrendas que comentaré más adelante.

Misas, rogativas y procesiones para atraer la lluvia son frecuentes no sólo entre las comunidades campesinas de los Andes, sino quizás en todas las culturas populares de

\footnotetext{
${ }_{4}$ Recoge este autor varios testimonios que, aunque de manera indirecta, aluden a la violencia de Sendero Luminoso y a la manipulación de esta creencia popular a la hora de imponer el terror entre las comunidades campesinas de Jauja y Ayacucho: los muertos abandonados en los campos, mirando al cielo, mirando al sol, ahuyentan a la lluvia y atraen la sequía y con ella el hambre.
} 
tradición cristiana. Sin embargo, varios autores han destacado el protagonismo de los niños en ritos y ceremonias sincréticas destinadas a propiciar la venida de las lluvias, niños cuya súplica, por la mera pureza de su espíritu, se considera más eficaz que la de un adulto (Van der Berg 1989: 71-72). Así, Cuba de Nordt (1971: 66) menciona como algo habitual las procesiones de niños que marchan arrodillados portando velas y cruces al tiempo que elevan a gritos súplicas al Señor para que mande su agua, su lluvia. Remarcando este sincretismo, y destacando seguramente por el detalle y la emotividad de la descripción, Rösing (1996: 252-255) registra un llamado de lluvia celebrado en 1987 por las gentes de Charazani (La Paz, Bolivia) en la Montaña del Rayo (Cerro del Corazón de Jesús según la toponimia oficial). Allí, en una ceremonia «marcadamente católica», se imploraba la misericordia de la Virgen del Carmen, de la Candelaria, del Señor, del Rayo y del Corazón de Jesús, elevando a estas entidades plegarias y ofreciéndoles velas y sahumerios. Junto con algunos adultos, fundamentalmente eran niños quienes imploraban, arrodillados hacia el Levante, con las velas en la mano, rezando (en español) varios Padrenuestros, Ave Marías y Credos, y gritando al Cielo (en quechua) para que enviase su lluvia de misericordia.

Pero al mismo tiempo que los niños cumplen con su papel de peticionarios preferentes, también quedan registrados casos en los que son convertidos en objeto de un maltrato destinado a provocar la clemencia de aquellas entidades con poder para enviar la lluvia sobre los campos. Niños que, como menciona Paredes (1995: 156), procesionan desnudos hasta lo alto de los cerros, para que su desnudez sirva de ofrenda y al mismo tiempo despierte en las alturas una mayor misericordia. $\mathrm{O}$ niños expuestos a la intemperie en las noches rasas del estío, haciendo penitencia por el conjunto de sus comunidades en el valle de Yanamarca (Jauja, Perú), pidiendo a Dios que mande lluvias que hagan fructificar los sembradíos y se aleje así la sombra del hambre (Tillmann 1997: 93). O niños desnudos que son maltratados en los campos, al tiempo que los adultos suplican lluvias en espera de que éstas acudan para aliviar el sufrimiento desmedido que están causando a las criaturas (La Barre 1948: 200; Tillmann 1997: 99-100).

Pero no sólo los niños se convierten en objeto de estos maltratos encaminados a despertar la conmiseración de los dueños de la lluvia, sino también diferentes animales, entre los cuales las ranas cobran especial protagonismo, sobre todo en la zona del Titicaca.

Rösing (1996: 162) apunta cómo algunos especialistas rituales kallawayas capturan ranas en el Titicaca, a las que golpean con varitas hasta que éstas lloran e imploran la misericordia de Dios para que llueva. Éste es el que algunos ritualistas de la región de Charazani (La Paz, Bolivia) denominan «el secreto de la rana». Sin embargo, el empleo de ranas para implorar misericordia suele estar más bien relacionado con su abandono en lo alto de peñas peladas ${ }^{5}$.

5 Poco sentido tiene entonces -por lo que a continuación referiré- el apunte ofrecido por Bandelier $(1910: 103,121,155)$ respecto de que especialistas rituales del Titicaca saquen ranas vivas del lago y vuelvan a arrojarlas al agua «para implorar la lluvia», en lo que él llama una «costumbre primitiva, es decir precolombina». Siendo el único autor que ha mencionado esta práctica, o faltan datos en su descripción etnográfica, o más bien pareciera que Bandelier entendió mal lo que le contaban, pues de ser simplemente así, ¿dónde está el castigo a la rana, por qué debiera ésta implorar misericordia? 
Para esta misma región del Titicaca, Vellard (1981: 171) señala que el ritualista acude a una fuente, recoge todas las ranas que puede y las lleva a algún pico rocoso, lejano y carente de agua. Allí, antes de abandonarlas, recita un Padre Nuestro y les ofrece libaciones, como también a la Tierra. El llanto de las ranas al verse desvalidas en las alturas y lejos de su natural medio acuático funciona entonces como una llamada a la lluvia. Particularizando para los habitantes de la Isla del Sol, este mismo autor matiza que una o dos ranas son encerradas en un vaso alto y estrecho -o en una olla, según Paredes (1995: 159)-, y abandonadas en el cerro que preside la isla. Las ranas lloran, y piden a los mallkus que envíen lluvia para que los vasos se llenen de agua y así ellas puedan escapar y regresar al lago arrastradas por las torrenteras.

Se trata de ranas indeterminadas o de una rana hembra, como registra Vellard (1981: 71) en algunos cantones meridionales del Titicaca, en territorio boliviano. En caso de que para noviembre todavía no llueva, el ritualista toma del lago un ejemplar de gran tamaño y asciende el Kaphia o Monte Cólera hasta alcanzar la laguna (encantada) de Wara Warani, Madre de todas las aguas, donde abandonará a la rana en medio de ofrendas y plegarias al cerro y a la laguna. Si por fortuna el llanto de la desvalida hembra fuera atendido por un macho, ese mismo día empezaría a llover.

Junto a las ranas, Van der Berg (1989: 69) apunta que algunos ritualistas depositan también algas del fondo lacustre que, al empezar a secarse, redundan en la apelación de compasión a las fuerzas de la Naturaleza. Señala además este autor que los batracios son recogidos después de ofrecer a las aguas del Titicaca un pequeño pago de coca e incienso. Por su parte, seguramente sea Del Carpio (1918: 41) el único en hablar de peces expuestos al sol en vez de ranas. Asimismo, Forbes (1870: 237), La Barre (1948: 182-183) y Ramos Gavilán (1976 [1621]: 82) apuntan que, en vez de ranas vivas, lo que se deja en lo alto de las peñas y de los cerros son imágenes de ranas, sapos y otros animales acuáticos, «idolillos» interpretados en el marco de una magia simpática propiciatoria; imágenes pétreas de sapos que Girault (1988: 307, 350-351) registra en ritos kallawayas de fertilización de los campos recién sembrados y que son regados con agua de lluvia o con agua de altura.

En este exponer ranas al sol de las alturas para que su croar se transforme en llanto de súplica, Tschopik (1968: 315-316; vid. también Llanque 1974: 26-27) indica que tanto la captura de los animales como la subida al cerro se lleva a cabo en medio de cantos alegres y hasta burlones, que se tornan, al abandonarlos y emprender el descenso, en tristes y lúgubres, de arrepentimiento y súplica. Más aún, a partir de una entrada de Bertonio, señala que el canto figura en la magia simpática para hacer llover de los aymaras desde el siglo XVII (Tschopik 1968: 272 n. 570). Sin embargo, de lo que en realidad habla el jesuita no es de cantos sino de gritos para atraer la lluvia: «Huaccalitha. Dar bozes los del pueblo como en procaSsion para que llueua, y diziendo, Huaccali huaccali, es rito Gentílico» (Bertonio 1984 [1612]: II, 141). Gritar y no cantar, entonces, como ya he recogido más arriba al hablar de procesiones, rogativas y visitas a los cerros pidiendo misericordia, que sería precisamente la traducción del grito en aymara indicado por Bertonio $($ huaccali $=$ wakalli $=$ waqali $)$. Por tanto, en esta dirección -y no en la apuntada por Tschopik- habría que mirar puestos a buscar continuidades desde la época prehispánica hasta el presente. 
Junto con las ranas, otros animales son también maltratados a fin de despertar misericordia por parte de las entidades tutelares que han de enviar la lluvia, y en estas prácticas será igualmente tentador establecer comparaciones anacrónicas. Así por ejemplo, remontándonos a la época Inca, Poma de Ayala (1987 [1615]: 246 [f. 255 (257)]) identifica al mes de octubre con las festividades del agua (Uma Raymi Quilla), indicando que en éste mes sacrificaban cien carneros (= llamas) blancos «a las uacas, principales ýdolos y dioses, para que les enbiasen agua del cielo», atando además en la plaza pública otros cien carneros negros y no dándoles nada de comer a fin de que llorasen de hambre. Según este autor, ataban también a los perros para que aullasen, golpeando a aquellos que no lo hacían, y los propios hombres y mujeres lloraban por las calles y plazas pidiendo a gritos que los dioses les enviasen lluvia. Una práctica, ésta de hacer llorar a las llamas, que según comenta Patch (1971: 7, cit. in Rösing 1996: 468) todavía persiste en comunidades aymaras de la provincia boliviana de Manco Cápac (La Paz) como parte de rituales celebrados durante el mes de octubre para llamar a la lluvia; ritos que en sí mismos constituyen un catálogo de formas de invocar la lluvia pidiendo misericordia según lo hasta aquí comentado. A fin de remediar la sequía, los campesinos primero suben al cerro más alto y, mientras ayunan, suplican por la llegada de las lluvias. Si éstas tardaran en llegar, amarran una llama negra y no le dan nada de comer hasta que llueva. Si la llama muriese antes de que empezara a llover, capturan ranas en el Titicaca y las abandonan en las cumbres más altas. Si la sequía persistiera y las ranas muriesen, el último recurso es enviar mensajeros a la cima del volcán Kaphia en busca de agua.

Por otra parte, en lo que se refiere a la práctica señalada por Poma de Ayala de hacer aullar a los perros a través del maltrato para atraer la lluvia, por poner otro ejemplo, Tillmann (1997: 98) registra la pervivencia de esta costumbre en la comunidad de Tingo (Jauja, Perú).

Y no podría cerrar este epígrafe sin mencionar el maltrato a los santos católicos, no sólo a los directamente relacionados con la lluvia y otros fenómenos meteorológicos (los santos Andrés, Lucas, Isidro Labrador, Santiago, Santa Bárbara, o las Vírgenes del Carmen y de la Candelaria), sino también los santos patronos de cada comunidad. A este respecto, Paredes (1995: 159) apunta que la comunidad de Arani (Cochabamba, Bolivia) sacaba en procesión a la imagen de San Isidro Labrador hasta las afueras del pueblo, abandonándola ahí hasta que lloviese. En una ocasión, cuenta, un borracho que caminaba de noche por la vega confundió la estatua con un salteador y le disparó varias veces; desde entonces, por miedo a que el santo tomase represalias y sumiese a la comunidad en una sequía perpetua, sustituyeron esta práctica por rogativas más piadosas.

Por su parte, Polia Meconi (1988: 93-95) menciona cómo a San Pedro Chicuatero, patrón de Huancabamba (Piura, Perú), se le restriegan los ojos con ají a fin de obtener la lluvia, bien como castigo por no haber escuchado las súplicas de la comunidad, bien porque el ají le hará llorar (entendiéndose sus lágrimas como metáfora de las gotas de lluvia); incluso a veces se maltrata físicamente su imagen, siendo entonces que el santo manda la lluvia para escapar del tormento. Asimismo, describe cómo en tiempo de secas el santo es sacado en procesión y presentado ante las casas de los campesinos, que le ofrecen frutas, flores, velas o dinero, y también súplicas para que 
venga la tan esperada lluvia y se conjuren los espectros de la sequía y de la peste bovina. Estas ofrendas se repetirán de nuevo en casa del pasante de turno, donde la imagen será alojada hasta que empiecen a caer las primeras lluvias del invierno; entonces el santo será devuelto de modo triunfal a la iglesia, vestido como un campesino más, engalanado con flores y papel de colores y acompañado de músicos y danzantes.

\section{Llamando lluvia a cántaros}

Al desarrollar la entrada «Uma hallu / Hallu uma (agua de lluvia)» en su diccionario aymara-castellano, Miranda (1970: 283) señala que, cuando no llueve, los campesinos afligidos acuden, con ceremonia y con ofrendas, a traer agua de alguna laguna de las alturas en un cántaro nuevo, y asperjan con ella sus chacras con la esperanza de que llueva. Una práctica sobre la que Arriaga (1920 [1621]: 139 [cap. XV]) ya había llamado la atención en sus indicaciones para el interrogatorio de hechiceros y la búsqueda de wakas al registrar la necesidad de preguntar a éstos «de qué lagunas traen cántaros de agua, para rociar la chácara, y pedir lluvia». Método para llamar a la lluvia éste que la extirpación de idolatrías no consiguió eliminar y que se torna pieza clave en la persecución del movimiento mesiánico desarrollado en Lircay (Angaraes, Huancavelica, Perú) en 1811, relacionado con Santiago y el Wamani (= cerro) (Pease 1974). Buscando propiciar la fertilidad de la Tierra y el retorno a una edad más venturosa, en contraste con un presente marcado por la pertinaz sequía, el retroceso en la minería y la crisis triguera que toda Huancavelica padecía a comienzos del siglo XIX, miembros de la comunidad suben al cerro para recoger agua de la laguna Cantalay en tres cántaros. De vuelta a la comunidad, en esta agua se hierve maíz, y con el resultado de la cocción se riega el cabildo, las cuatro esquinas de la plaza y se pretende asperjar también la imagen de Santiago encerrada en la iglesia, motivo este último de tumulto, represión por parte de las autoridades e inicio de una investigación judicial.

Podríamos decir que tal fue la persistencia de esta práctica, que quizás sea una de las más señaladas en la literatura etnográfica sobre llamados de lluvia y ritos agrarios en general; una práctica en la que es frecuente encontrar alusiones no sólo al empleo del agua de altura proveniente de las lagunas para regar los campos, sino también al agua salada del mar. Según Antúnez (1986: 58), la lógica aplicada a este método tiene que ver con el aumento de la humedad atmosférica, ya que el agua asperjada se volatiliza casi inmediatamente. En este sentido - prosigue este autor-, el agua marina, más fría y salina, resulta mejor inductora para la lluvia: no sólo se evapora antes, sino que además entronca con la creencia de que las nubes de la cordillera bajan en invierno a beber a la costa, para luego en primavera volver al altiplano cargadas de agua. Así por ejemplo, Cuba de Nordt (1971: 67) apunta el dato de que en Jicamarca (Lima, Perú) contrarrestan la sequía con agua de mar recogida entre Ancón y Chancay, agua que los ritualistas vierten de noche, sin que nadie pueda verlos, sobre las pampas resecas al tiempo que realizan bailes e invocaciones.

Volvamos sobre la ya mencionada peregrinación kallawaya al volcán Tuana descrita por Oblitas Poblete (1978: 179-184). Doce mozos encabezados por el especialista ritual de la comunidad, todos ellos vestidos con sus mejores galas, acuden a los 
pies de la montaña portando banderas blancas, sombrillas de plumas de suri y hondas, tocando bocina, erque y quena. Allí, después de una breve ceremonia y ofrenda, ejecutan la Danza de los Cutichej («los que transforman»), una carrera vertiginosa culebreando en círculos agitando violentamente los objetos portados al tiempo que gritan y emiten chasquidos con sus hondas; su intención es agitar el ambiente y poner en alerta a los elementos de la Naturaleza. Después de ascender a la montaña en absoluto silencio, al llegar a la cumbre vuelven a danzar alrededor de la laguna, a la que sacrifican cuyes y un llamo, cuya sangre es asperjada a la laguna y al volcán. Los mozos mojan en las aguas de la laguna guijarros recogidos ex profeso en sus chacras y los lanzan con sus hondas en dirección a las sementeras, al tiempo que el ritualista eleva sus plegarias y recoge agua con la que, de vuelta a la comunidad y en medio de gran alborozo vecinal, regará los campos, reservando una parte para verter en los manantiales que nutren los canales de riego y otra parte para dar de beber a los asistentes como «agua bendita que proporciona salud y buenaventura».

Sin embargo, las creencias populares no siempre exigen extraer grandes cantidades de agua de estas lagunas de altura con la que luego regar los campos de cultivo. Así por ejemplo, Tillmann (1997: 105-111) registra el caso de diferentes comunidades campesinas de la vertiente oriental del valle del Mantaro (Jauja, Perú) que acuden a la laguna de Tamias a recoger agua con la que regular simbólicamente la afluencia de lluvias y combatir la sequía. En términos generales, una comisión de la comunidad asciende procesionalmente al cerro donde se encuentra esa laguna, y el especialista, teniendo sumo cuidado de no molestar en exceso a la laguna, lanza al centro de ésta un porongo atado a una cuerda; apresada el agua, cual si se huyera de un robo, esta comisión emprende un apresurado regreso a su comunidad, donde celebrarán rogativas y misas que refuercen la eficacia de esta acción ritualizada. Con esa agua pueden asperjarse los campos, aunque lo más habitual es guardarla, y devolvérsela a la laguna una vez que empiece a llover, cuando la lluvia sea la adecuada, o cuando se desea que escampe.

Y es que a veces un poco hace mucho. En un paso más allá en la metonimia, Polia Meconi (1988: 89-92) refiere en su trabajo sobre las lagunas de los encantos cómo lo verdaderamente importante es «agarrar» la esencia de la laguna, sin que resulte necesario extraer más que una mínima cantidad de agua de ella. Así, informa de que las gentes de Huancabamba (Piura, Perú) acuden a la laguna Negra a capturar su $m a-$ mayacu (virtud purificadora, fertilizante y terapéutica de las aguas sagradas). De ello se encarga el ritualista, que tras desplegar una compleja mesa de ofrendas y arrojar a las aguas parte de ellas, coloca un vaso de barro en el extremo de una caña larga que introduce en la laguna y con la que remueve el fondo hasta «agarrar» su mamayacu; con el contenido de este vaso se riega la mesa y, desde el cerro en donde se encuentran, se asperja en dirección al valle y a los campos de cultivo, esperando que llueva. Esta esencia de la laguna a veces queda representada en algas y pequeñas plantas del fondo lacustre que, por la acción de removerlo se desprenden y pasan al vaso; otras veces simplemente está ahí, el ritualista sabe que la ha «agarrado». 


\section{Agitando las aguas, molestando a la laguna}

En perfecta consonancia con su interpretación meteorológica de la práctica de asperjar los campos resecos con agua de altura o de mar, Antúnez (1986: 58) señala que, al provocar oleaje, aumenta en las lagunas la humedad ambiental, la evaporación y los niveles de condensación atmosférica, todo lo cual deviene en la aparición de nubes de lluvia. En este sentido, eso es precisamente lo que las gentes del altiplano buscan al agitar las aguas: activar a los elementos para propiciar la lluvia. Arriaga (1920 [1621]: 139 [cap. XV]) lo recoge en sus instrucciones contra hechiceros y wakas al destacar la pregunta de «a qué lagunas tiran piedras, para que no se sequen, y vengan las lluvias». Y esto es precisamente lo que Bandelier (1910: 155) registra entre los habitantes de la Isla del Sol, en el Titicaca: ascienden a la cima pelada del monte llamado Calvario y desde allí lanzan piedras contra el lago para conjurar la sequía.

Por su parte, Tillmann (1997: 108) señala que las gentes de la comunidad de Quero (Jauja, Perú) que ascienden hasta el paraje de Tamias a recoger agua, lo primero que hacen es arrojar piedras a la laguna; entonces, dicen, levantan las nubes, y ése es el momento idóneo de coger el agua y rápidamente emprender el descenso, confiando en que estas alborotadas nubes pluviales les persigan de vuelta a la comunidad. Una creencia ésta que se extiende por varias comunidades del valle oriental del Mantaro: si la vuelta a casa con el agua arrebatada a la laguna se hace especialmente cansada, si los vientos dificultan el poder caminar, si las brumas ocultan el camino, entonces resulta evidente que la laguna se ha molestado por la acción de los hombres, y de seguro que empezará a llover pronto (Tillmann 1997: 105-111).

Si recién veíamos cómo el ritualista encargado de capturar la esencia de la laguna Negra citado por Polia Meconi actúa con sumo cuidado evitando causar molestias, Rösing refiere justo lo contrario al describir los llamados de lluvia de diferentes comunidades kallawayas y aymaras del altiplano de La Paz (Bolivia). Por poner un par de ejemplos representativos, las gentes de Khaata (kallawayas), mientras el especialista ritual extrae el agua de las alturas, se dedican a arrancar con violencia plantas acuáticas y flores y yerbas de la orilla, todo ello con el ánimo de molestar al lago (Rösing 1996: 344-345). Un paso más allá van los vecinos de Upinhuaya (aymaras): mientras que los varones tocan música destemplada y danzan alrededor del lago Pachacota, las mujeres lanzan piedras al agua, arrancan plantas y flores de la orilla y, como al descuido, extraen agua del lago; de vuelta en la comunidad la harán casar con otras antes de ejecutar las pertinentes ch'allas con las que esperan atraer a la lluvia (Rösing 1996: 363).

\section{El casamiento de todas las aguas}

Venimos viendo entonces cómo parte de la eficacia ritual de los llamados de lluvia tiene que ver con la mezcla de aguas de distinta procedencia, bien sea por el poder que concentran sus lugares de origen, bien en referencia a una simbiosis masculinofemenino por la cual el agua se transforma en elemento fertilizador de los campos. Una unión que, en virtud de este último simbolismo, suele equipararse con un casa- 
miento, el casamiento de todas las aguas, las de lagos y lagunas entre sí, las de éstos con aguas de manantial, las aguas que surten a las comunidades con las de lagos y manantiales, las aguas del cerro con las que corren por los canales de riego... todas las aguas entre sí, cuantas más mejor, aunque sin olvidarse de las calidades de cada una de ellas y prestando atención a esas aguas peligrosas (vid. supra) que podrían desencadenar efectos adversos. Y si esas aguas no se conocen entre sí, mejor que mejor, ya que ello les hará entrar en competencia a la hora de llamar a la lluvia con mayor efectividad. A esta lógica responde el hecho de que cuando en noviembre de 2004 asistí a la celebración del llamado de lluvia (chawpincha) anual que celebran las gentes de Santiago (Nor Lípez, Potosí, Bolivia) (Gil 2008: 230-234; s/f) se me recriminara, entre bromas y seriedades, no haber aportado agua de España; a aquel casamiento concurrían aguas del entorno inmediato de la comunidad, de La Paz, de Chile (aportada por un vecino que volvía de trabajar en las minas de Calama justo para la celebración de rito), de Oruro (que los hijos allí residentes de un vecino de la comunidad habían mandado a sus padres ex profeso), y habría sido «lindo» que yo hubiera contribuido con un agua «tan lejana».

En este sentido, Cuba de Nordt (1971: 66) refiere que, a fin de paliar la sequía padecida en Chinchero (Urubamba, Perú) en 1969, un grupo de jóvenes de la comunidad peregrinó a coger agua del río Vilcanota y de las lagunas de Waypo y Piuray, que luego acudieron a verter en la laguna Timpoccocha; cuatro aguas desconocidas entre sí que entraron entonces en una furiosa competencia de la que acabaron por surgir nubes de lluvia que al instante descargaron sobre Chinchero. Tan lluvioso resultó aquel verano que los periódicos no tardaron en hacerse eco de la noticia, en buena parte porque los habitantes de la vecina Paucartambo elevaron una protesta formal habida cuenta de lo que consideraron un robo de lluvia al resto de comunidades de la región mediante prácticas mágicas y la aplicación de lo que se popularizó como un «secreto de los incas».

Si bien todo queda envuelto en lo ceremonioso del rito, este casamiento de las aguas puede realizarse de manera expeditiva o recargarse de complejos simbolismos, siendo además que las aguas pueden mezclarse con otros líquidos (p.ej. vino, tal como ha quedado dicho) o con preparados especiales. Así por ejemplo, en el chawpincha de la comunidad de Santiago se utilizan, además de las diferentes aguas aportadas por los presentes, seis botellas que contienen las «bebidas para el cerro», mezclas de agua con coa, confitados, chocolate, semillas de coca, harina de quinua y harina de maíz (Gil s/f).

Valderrama y Escalante (1988: 96-105, 155, 209) señalan que en la comunidad de Yanque (valle del Colca, Perú) se utilizan tres botellas como uno de los elementos fundamentales de la mesa ritual para llamar a la lluvia. En ellas se recoge agua de la toma principal del canal Mismi, el manantial principal del Tata Mismi -junto con el Waranqate, los nevados más elevados en las márgenes del río Colca-, del ojo del manantial Umahala y de las playas de Camaná, en Arequipa; las tres llevan un atadito de coca en el cuello, y van coronadas por un pompón de algodón natural a modo de tapón, que simula nubes que quieren llover. En el trascurso del ritual, estas aguas casarán entre sí y con sendas botellas de vino y alcohol, asperjándose el líquido resultante en dirección a los cerros, los manantiales y los campos de cultivo. Ya a lo largo del 
año los yanqueños han estado mezclando el agua de mar con las aguas de manantial, echándola a poquitos en los manantiales para evitar que éstos se sequen y propiciar su abundancia; la cuestión es que ambas aguas entren en competencia, se enojen, y de su riña aparezcan las esperadas nubes de lluvia. Pero lo realmente importante de esta unión de aguas es que al mismo tiempo que celebran un matrimonio, los yanqueños propician una unión sexual: el agua del Mismi, proveniente del deshielo de la cumbre del cerro es considerada masculina, mientras que la del Umahala es femenina; esta mezcla de aguas convertirá así al líquido elemento en fuente de vida que fecunda los campos, en el semen del cerro que, a través de los canales de riego, fecunda los sembradíos (Valderrama y Escalante 1988: 206, 209).

La misma idea de la unión matrimonial operaría en el llamado de lluvia celebrado por las gentes de Quiabaya (La Paz, Bolivia), descrito por Rösing (1996: 265-318); un matrimonio entre las aguas de los lagos T'iliakán (masculino) y Titiakán (femenino), sancionado por los difuntos de la comunidad, Santiago Apóstol, los cerros y el viento Ankari. Se trata de un casamiento de aguas que tiene lugar no en las alturas, sino en la propia comunidad, en medio de un ambiente absolutamente festivo, con banquete (de bodas, cabría decir) incluido, tras el cual se acude a ch'allar los manantiales de los que se abastece el pueblo con esa agua enriquecida, complementada, presentándoles además algunas ofrendas.

Frente a estos ejemplos, mucho más «sencillo» resulta el intercambio de aguas practicado por comunidades aymaras al sur del Titicaca: cuando la sequía persiste y el llanto de las ranas no ha surtido efecto (vid. supra), varios ritualistas se reunirán un martes (día de «los malignos») para ascender el Kaphia o Monte Cólera portando agua del lago, que verterán en la laguna de Wara-Warani. Asimismo, recogerán agua de ésta para verterla en el Titicaca, confiando en que este casamiento traiga consigo la tan esperada lluvia (Vellard 1981: 171-172).

\section{Conteniendo a los vientos}

Ya he señalado el protagonismo de los vientos a la hora de desplazar las nubes pluviales de un cerro a otro, o su interpretación como buen augurio por parte de aquellos que descienden de la laguna de Tamias tras haberle «robado» su agua. Sin embargo, en esto de llamar a la lluvia los vientos no suelen ser bienvenidos, en especial los que soplan del oeste, que más que traer a las nubes las llevan en sentido contrario. Son éstos los «vientos malvados, vientos de tempestad» que -señala Polia Meconi (1988: 90-91) - tratan de contener las gentes de Huancabamba (Piura, Perú) a través de las plegarias recitadas al desplegar sus ofrendas a orillas de la laguna Negra, y de las pronunciadas al tiempo que invocan a ésta y a los cerros para que envíen su lluvia.

Estos mismos vientos del oeste, «vientos malos», wasayayas, son los que tratan de asustar las mujeres de Santiago (Nor Lípez, Potosí, Bolivia) gritando al final del chawpincha, tras las últimas ch'allas a los dos cerros tutelares de la comunidad (Qaral y Lliphi) y las plegarias (en quechua) elevadas tanto a éstos como a la Pachamama y a Santiago Apóstol, a las comunidades vecinas y a todos «los sedientos», acompañadas de un Padrenuestro (en español). Aunque estos vientos ya habían sido 
tratados de bloquear con una acción ritual previa: mientras se sacrifica la llama que ha de servir de pago al cero Qaral y se va componiendo la mesa de ofrendas, uno de los ritualistas procede a enterrar (en un deposito identificado y de uso recurrente en cada celebración anual) el torolunqu, una figurita de sebo y pelo negro de llama que representa a un toro y cuyo cometido es el de embestir contra estos vientos del oeste; si hubiera un cabrito negro que sacrificar como pago al cerro, su cabeza también sería enterrada aquí con la misma función simbólica (Gil 2008: 233-234; s/f).

Se trata pues de bloquear a los malos vientos, algo que en los llamados de lluvia kallawayas descritos por Rösing parece cobrar especial repercusión. Ankari, es el viento $^{6}$ que habita en el interior de la tierra y que sopla a través de una enorme puerta (representada en las cavernas y grutas del paisaje), alejando así las nubes de lluvia. Es necesario entonces cerrar esta puerta, para lo cual se le ofrece el pago de alcohol puro y un huevo. Mientras que la ch'alla de alcohol es para el Ankari -puntualiza Rösing (1996: 215-219, 345-347) - el huevo va destinado al Rayo, cuya «bala» representa; un Rayo, como ha quedado dicho, que gusta de fastidiar a su hermana la Lluvia y que propicia la sequía.

En esta línea, Vellard (1981: 169) recoge el dato de que en Playa Verde, cerca de Oruro (Bolivia), se entierra una llama viva cargada de costales de sal para llamar a la lluvia. Según Van der Berg (1989: 72), este proceder tendría que ver con la idea de que la sal atrae el frío y las heladas, además de simbolizar a los vientos del oeste, que son precisamente los encargados de llevarse las nubes pluviales, malas influencias todas ellas neutralizadas así al enterrar la sal. De acuerdo, pero ¿por qué no pensar simplemente que con este acto se está dando de comer sal a la Tierra, a la Pachamama, que misericordiosamente recibirá entonces agua de lluvia para aplacar su sed, entroncando así con esas otras lógicas planteadas más arriba?

\section{La lluvia y los ancestros}

En lo alto de los cerros, a orillas de los lagos, habita la lluvia pero también los antepasados, y ambos garantizan el bienestar de las comunidades al propiciar el crecimiento de las plantas y la reproducción de los ganados. De ahí el papel de éstos en los rituales para llamar a la lluvia, que generalmente se realizan además en noviembre, el mes de los difuntos, tiempo en el que han de caer las primeras lluvias. Es por ello -según Rösing (1996: 219-222) - que este vínculo entre la lluvia y los ancestros no pasa por los muertos antiguos, los gentiles, los chullpas, sino por los difuntos, la comunidad de los muertos, que junto con la comunidad de los vivos constituye la comunidad, el ayllu. Sin embargo, esos otros muertos antiguos no quedan exentos de los llamados de lluvia sino todo lo contrario, cobran a veces especial protagonismo.

6 Matiza Rösing (1996: 514) que el Ankari, entendido como divinidad del viento entre los kallawayas, puede variar de significado en el altiplano (por encima de los $4.000 \mathrm{msnm}$ ) y en el valle (comunidades en alturas próximas a los $3.800 \mathrm{~m}$ ). Mientras que en el primer entorno es considerado como «negativo», «malo» y dañino, en el segundo se le considera como «bueno», «servidor», mensajero de las entidades tutelares, cuya tarea es llevar a sus respectivos destinatarios las ofrendas entregadas por los hombres; en este sentido, Ankari, viento y servicio son sinónimos que aluden a una misma entidad. 
Recordemos al respecto la referencia aportada por Valiente (1986: 90) en su descripción de la Fiesta del Agua en Puquio (Ayacucho, Perú) acerca de que las ofrendas destinadas al cerro Pedrorko y a la laguna Qoricocha son depositadas en un pukullo o tumba de los gentiles.

Por su parte, Polia Meconi (1988: 92-93, 95-96) señala una estrecha relación de los muertos con la abundancia de cosechas, y remarca una asociación entre los huesos antiguos y la lluvia, y entre la muerte y la fecundidad. En su descripción del «rito del gentil de invierno» describe cómo en la cara del cerro Jalqueño que mira hacia Huancabamba, hay una gruta (la Cueva de los Gentiles) en la que se reúnen gran cantidad de restos óseos, y adonde acude el especialista para poner en práctica un ritual propiciatorio de lluvias. Citando el testimonio de Ramírez (1970: 66-67), este autor describe cómo el maestro elige una calavera -que debe tener color amarillento- a la que ofrenda maní, azúcar, alcohol y perfumes, y que sitúa a la entrada de la gruta; al tiempo que adula su virtud, la amenaza con no regresarla al osario hasta que no haga llover suficientemente sobre los campos. Una vez que ha llovido bastante, el especialista agradece a este gentil de invierno por sus servicios, lo reintroduce a la cueva y saca entonces, repitiendo las ofrendas, la calavera -blanquecina- que representa al gentil de verano, cuya virtud consiste en hacer cesar el aguacero. Lo llamativo de este rito del gentil de invierno es que el especialista trate con huesos de chullpa para atraer las lluvias, pues generalmente en el altiplano se sitúa a los chullpas en un tiempo antediluviano marcado por la oscuridad salvaje, que termina con la primera aparición del Sol en el firmamento, un Sol abrasador que secó a los chullpas y sumió a su mundo en la más pertinaz de las sequías. En este sentido, lo habitual es recurrir a los gentiles con el fin de hacer cesar las lluvias (v.gr. Bandelier 1910: 118, $158 \mathrm{n}$. 140; Llanos 2004: 177 y ss.; Paredes 1995: 160) y no para atraerlas, práctica que sí coincide con el rito del gentil de verano.

Tomando igualmente los cráneos antiguos como instancia de invocación, Tillmann (1997: 111-112) apunta que en la comunidad de Huertas (Jauja, Perú), mantienen una especial relación con ciertas calaveras que nunca están desatendidas: a ellas se les ofrece cigarrillo, hoja de coca, trago, velas y agua bendita. No especifica este autor si se trata de calaveras anónimas o individualizadas, si de gentiles o de difuntos, si se custodian o no en altares, si en el ámbito doméstico o en otro lugar; en cualquier caso, esta relación con los cráneos recuerda mucho al culto a las ñatitas que se practica en zonas del altiplano boliviano y en especial en La Paz, para el cual, sin embargo, no está descrita en términos específicos una relación directa entre los difuntos y las lluvias (v.gr. Fernández 2010).

\section{Mesas blancas, mesas negras ${ }^{7} \mathrm{y}$ otros pagos}

«Todo el altiplano sufre sequía. La Pachamama, la que sustenta la vida, ya está vieja. Hemos puesto diez fetos de llama, diez fetos de oveja, hierbas koa, coca, dulces, kaitos

\footnotetext{
7 Mesa es la preparación de ofrendas a modo de platos sacrificiales que son presentados a las entidades tutelares como parte fundamental del ritual. Ahora bien, según el destinatario o el propósito del ritual (magia blanca o negra), tanto los ingredientes como el modo de componer el plato varían notablemente. Sin entrar
} 
[= hilos] de colores y mucho aguardiente en la cima del cerro; todo ello lo hemos quemado para que en humo se deshagan los males y caiga lluvia, pero nada ha sido posible conseguir. La tierra está vieja, y como toda vieja, es sorda».

Con estas palabras describe Botelho (1982: 69) en su novela etnográfica Altiplano el pago que unos comunarios ofrecen al cerro y a la Pachamama a fin de que éstos envíen su lluvia; una descripción en la que se dan cita la mayoría de los ingredientes presentes en la mayor parte de ofrendas y pagos empleados en los llamados de lluvia. Sin embargo, el problema en este campo radica en que, teniendo en cuenta que buena parte de la literatura etnográfica no dedica a los llamados de lluvia más que menciones puntuales o informaciones fragmentarias, no es habitual que se preste especial atención a las ofrendas, salvo en aquellas descripciones más completas.

Contando con este inconveniente, he mencionado hasta aquí diferentes tipos de ofrendas a modo de libaciones, ya se trate de preparados líquidos (ch'uwa) con las que se dará de beber a las entidades tutelares «sedientas», con las que se regarán los campos o que se verterán en canales de riego, manantiales y lagunas, desde la lógica del casamiento de las aguas. Asimismo he presenciado mesas compuestas por ingredientes diversos, y sacrificios animales que son presentados como pago a cerros o lagunas. A continuación me gustaría incidir sobre estos dos puntos, de cara a penetrar la lógica interna de las mesas y la razón de ser de los sacrificios. Empecemos por estos últimos.

Apoyándose en la visita en 1622 de Hernández Príncipe a Recuay (Ancash, Perú), Limón (2006: 100) sentencia que el sacrificio de llamas tiene un especial significado a la hora de atraer la lluvia, porque en los orígenes éstas -como los humanos- salieron al Mundo desde sus pacarinas, a saber: los lagos y las lagunas ${ }^{8}$. Una relación agua-llamas igualmente remarcada por Greslou (1990: 19), quien insiste en que las llamas son hijas de las lagunas, y que por eso constituyen el sacrificio primordial a la hora de atraer las lluvias: ante la muerte de sus hijas, la madre Agua se compadecerá de las llamas y accederá a caer sobre los pastos y los sembradíos afectados por la sequía; un medio para inspirar la misericordia del Agua similar al de hacer llorar a las llamas, tal y como antes se señaló.

Junto a las llamas, podría decirse que también los cuyes constituyen el sacrificio por excelencia a la hora de pedir lluvia. Mientras que las primeras son presentadas como pago a los cerros o enterradas a orillas de las lagunas, los cuyes -seguramente por una cuestión de tamaño y manejabilidad- son arrojados a las aguas. Así, al describir las ofrendas kallawayas a la laguna del volcán Tuana, Oblitas Poblete (1978: 179-184) indica cómo la sangre de los cuyes y el llamo sacrificados son asperjados a la laguna y el cerro, arrojados los primeros a las aguas y enterrado el segundo en la

en detalle en la cuestión de las instancias de invocación, es mesa blanca la destinada «para» o «a favor de» circunstancias positivas (salud, bienestar, buena cosecha, etc.). Por el contrario, la mesa negra va destinada «contra» algo o alguien, ya sea con el propósito de causar un daño de manera intencional o para revertir un mal causado.

8 Si bien la autora toma el testimonio de Hernández Príncipe como base para una generalización, lo que realmente apunta el visitador no es sino un dato puntual que habría que contrastar con otras mitológicas, señalando en concreto que «esta población [de Chaupis] está convecina a la de Hecos, y los carneros de la tierra [= llamas] desta población y la otra fingen procedieron de la laguna de Querococha, por lo cual la adoraban en reconocimiento» (Hernández Príncipe 2003 [1622]: 758). 
orilla, al tiempo que «mesas complejas» (?) son ofrecidas a la laguna y el volcán. Del mismo modo, en su análisis del movimiento mesiánico organizado en 1811 en Lircay (Angaraes, Huancavelica, Perú), Pease (1974) señala que, antes de recoger el agua de la laguna Cantalay, se ofrecían a ésta doce cuyes, coca, vino, flores, granos de maíz crudos y diversos alimentos cocinados, todo ello acompañado de sahumerios, cantos, danzas y toques de tamborcillo, campanilla y cornetas.

Mientras que estos autores nada dicen acerca del color de los animales sacrificados, y tampoco de cómo se recoge el agua de estas lagunas, Rösing (1996) sí especifica que cuando se trata de agitar las aguas de las lagunas, de molestarlas, estos cuyes ofrecidos suelen ser ejemplares de color negro, pues éste es el color de la ofrenda destinada a provocar la rabia del receptor, de una ofrenda propia de magia negra, aquella destinada a propiciar el mal, a molestar. En el caso de Charazani y de otras comunidades kallawayas y aymaras del entorno del Titicaca en Bolivia, la autora señala esta ofrenda como el ingrediente fundamental de las mesas negras destinadas a soliviantar a las lagunas, pues, como señalan varios de sus informantes, se trata de hacer rabiar al lago, de ponerlo furioso, de «hacer hervir su agua» para que envíe nubes negras, nubes de lluvia (Rösing 1996: 226, 227, 236).

Pero no sólo pareciera existir un código de colores a la hora de molestar a las aguas. Sobre esto, la propia Rösing menciona reiteradamente que no puede usarse algodón blanco, ni claveles blancos, ni cuyes blancos ni cualquier otro elemento de este color en pagos y ofrendas destinados a llamar a las lluvias, pues las nubes de pluviales no son blancas; al utilizar este color más bien se estarían atrayendo las nubes equivocadas, y por ende alejando la tan ansiada lluvia. Por lo mismo, tampoco las ofrendas deberían quemarse, ya que ello generaría un calor añadido y atraería a la sequía (Rösing 1996: 218,363); por eso los pagos descritos por esta autora o se arrojan al lago o se entierran en su orilla. Ahora bien, tengamos en cuenta que esta lógica de los colores y los calores tiene su sentido en tanto en cuanto que los llamados de lluvia descritos por Rösing constituyen fundamentalmente ritos coyunturales celebrados en momentos de sequía o de retraso de las lluvias. Por el contrario, en comunidades donde estos rituales se desarrollan con cierta periodicidad, sí es habitual la quema de sahumerios y de algunas ofrendas, aunque ciertamente no de manera generalizada ${ }^{9}$.

Así por ejemplo, a la hora de sacar agua del lago T’iliakán para después hacerla casar con la del Titiakán (vid. supra), las gentes de Quiabaya (La Paz, Bolivia) le entregan un feto de llama cargado con un costal de coca, sebo de llama, claveles, azúcar, etc. ${ }^{10}$. Hunden este pago en sus aguas, enterrándolo bajo la Gran Piedra del Cabildo, la Piedra Blanca (Yuraq Rumiyoc), a poca distancia de la orilla (Rösing 1996: 283 y ss.). Por su parte, también los kallawayas de Khaata (La Paz, Bolivia) ofrecen al lago Pachacota $-\mathrm{o}$ al que en ese momento sea poseedor de la lluvia, vid. supra- un feto

9 Tengamos presente en este punto que el modo de hacer llegar las ofrendas a las entidades tutelares andinas ha sido siempre a través del fuego. El especialista ritual prepara la mesa de ofrendas cual si de un plato culinario se tratase, que la instancia de invocación correspondiente degustará una vez quemada (cocinada); el humo eleva a las alturas la esencia de la ofrenda y así el receptor la recibe.

10 En realidad, matiza la autora, se trata de una mesa blanca amorosamente preparada siguiendo el orden establecido, recogida después cuidadosamente para darle la apariencia de un costal y cargado éste sobre el feto de llama. 
de llama acompañado de complejas mesas de hasta 24 platos preparadas en la orilla. Un pago que se acompaña del sacrificio de varios cuyes negros y de una llama o una alpaca, leyéndose sus entrañas y corazón en busca de indicios sobre la cantidad de lluvia que caerá ese año (Rösing 1996: 343-344).

En contraste con esta preeminencia del negro, he venido recopilando distintas ofrendas y pagos marcados por el color blanco, como blancas son también las banderas que agitan los kallawayas que, en su ascenso al volcán Tuana, agitan para perturbar la paz de los elementos y avisarles de su aproximación y sus intenciones (Oblitas Poblete 1978: 179-184, vid. supra).

Por citar un caso de convivencia entre las ofrendas blancas y las negras, Polia Meconi (1988: 89-92) señala entre las ofrendas presentadas a la laguna Negra al tiempo de pedirle perdón por «agarrarle» su mamayacu, alcohol, perfumes, maíz blanco, flores blancas, miel virgen, tabaco y monedas de plata que se depositan en la orilla, así como un cuy negro vivo que es arrojado a las aguas, para que la laguna se distraiga queriendo atraparlo y no se de cuenta de la maniobra del ritualista.

$\mathrm{Y}$ es que, salvo cuando se trata de agitar las aguas y molestar a las lagunas, no es condición sine qua non ofrecer mesas negras ni aplicar magia negra para que el llamado de lluvia tenga éxito. Más bien, todo lo contrario. Como botón de muestra podría citarse en este punto -y para terminar- la lógica interna del llamado de lluvia celebrado en la comunidad kallawaya de Chari, en el área de Charazani (La Paz, Bolivia). De acuerdo con la descripción de Llanos (2004: 166-167), constituyen ingredientes de este ritual celebrado anualmente en la segunda semana de septiembre, flores, fetos de alpaca, cuyes y diversos productos -sin especificar- aportados por toda la comunidad según pisos ecológicos, más un llamo blanco aportado por aquellos vecinos que poseen los rebaños más numerosos, más todas las aguas que los miembros de la mesa directiva sindical hayan podido acopiar de diferentes lagos, lagunas y manantiales -a condición de que el lugar esté a más de un día de caminata-. Dirigen el ritual tres «ritualistas blancos» (de magia blanca) más tres mujeres, entre las cuales lo ideal sería que dos fuesen niñas

\section{Consideraciones finales}

A partir de estos epígrafes he tratado de sintetizar diferentes modelos de llamado de lluvia en los Andes, aprovechando cada uno de ellos para plantear especificidades pero al mismo tiempo para establecer correlaciones entre diferentes lógicas rituales. De todos ellos cabe extraerse la conclusión de que los llamados de lluvia constituyen ritos colectivos, dirigidos por uno o varios ritualistas reconocidos, pero en los que participa toda la comunidad de acuerdo con sistemas de género, edad, rol y estatus. Más allá de las especificidades, el menú de ofrendas para atraer a la lluvia es compartido, como también lo es el elenco de instancias de invocación, si bien entre todas ellas destacan los cerros y las lagunas, el espacio simbólico sacralizado de las alturas.

Si bien los llamados de lluvia siguen pautas comunes, circuitos, esquemas lógicos, comportamientos y lenguajes prescritos, lo cierto es que no existe en el conjunto un patrón unitario y obligado. En tanto que estos ritos ponen de manifiesto un modelo 
de relaciones de reciprocidad entre la sociedad humana, la sociedad no humana (entidades tutelares diversas) y la Naturaleza, cada comunidad operará de acuerdo con su propia concepción del Mundo, su propia concepción del paisaje y su propia concepción de la Naturaleza. Por este motivo los llamados de lluvia, a pesar de los lugares comunes y de los elementos compartidos que he ido reseñando, son casi tan variados como las comunidades que los ejecutan, variedad que habla asimismo de condiciones históricas, nuevos y viejos modelos, continuidades y anacronismos, nuevas creaciones, sincretismo religioso, etc. He aquí una de las principales complicaciones a la hora de plantear un ejercicio de síntesis como el que aquí he tratado de presentar.

Junto con esta variabilidad del conjunto, y quizás como consecuencia de ella, el otro problema fundamental a la hora de abordar un estado de la cuestión sobre los llamados de lluvia es su propia consideración en la literatura histórica y etnográfica. Para unos se trata de tradiciones invariables que han perdurado desde el siglo XVI (o incluso antes) hasta la actualidad. Y a la vez, rituales vivos que se han ido adaptando a los tiempos, incorporando elementos diversos, reinterpretando imaginarios locales y regionales, reflexionando sobre las contradicciones, ajustándose al estilo propio de cada ritualista, etc.; todo ello remarcando una dialéctica entre lo pautado por la tradición, lo vivido por los hombres, las necesidades de cada comunidad y la idiosincrasia medioambiental de cada área concreta. Esto es lo que permite que los llamados de lluvia puedan variar tanto en lo particular a pesar del marco de sentido general. Para empezar, su simple consideración como ritos coyunturales vinculados con momentos de necesidad o ritos anuales ligados a los ciclos agrarios.

Podría entonces decirse que cada llamado de lluvia es único, como específica es la manera en que cada comunidad se relaciona con el medioambiente en que habita, el modo en que cada Cultura se relaciona con $s u$ Naturaleza. Mediante estos rituales los hombres conversan con sus entidades tutelares, se ponen de acuerdo y se comprometen mutuamente en prestarse servicios, pues la reciprocidad, en los Andes, va más allá de lo humano.

\section{Referencias bibliográficas}

AntúNEZ DE MAYolo R., Santiago Eric

1986 «El riego en Aija». Allpanchis 18 (28): 47-71. Cuzco.

Arriaga, Pablo Joseph de

1920 «Extirpación de idolatría en el Perú» [1621], en Colección de libros y documentos referentes a la historia del Perú, Segunda Serie, Vol. 1, pp. 1-214. Lima: Imprenta y Librería Sanmartí y Cía.

BANDELIER, Adolph

1910 The islands of Titicaca and Koati. Nueva York: Hispanic Society of America.

BARThEL, Thomas S.

1986 «El agua y el festival de primavera entre los atacameños». Allpanchis 18 (28): 147-184. Cuzco. 
BERTONIO, Ludovico

1984 Vocabulario de la lengua aymara [1612], edición facsimilar. Cochabamba: CERES - IFAE - MUSEF.

Calancha, Antonio de la, y Bernardo de Torres

1972 Crónicas agustinianas del Perú, selección de textos y edición crítica a cargo de M. Merino. Madrid: Consejo Superior de Investigaciones Científicas.

Cuba de Nordt, Carmela

1971 «Ritos de lluvia». Allpanchis 3: 6-67. Cuzco.

Del CARPio, Wenceslao

1918 «Breves aclaraciones etimológicas a la obra Las Islas del Lago Titicaca y Coati del señor Adolfo F. Bandelier». Boletín de la Sociedad Geográfica de La Paz 16 (47): $1-57$.

FERnÁNDEZ JuÁREZ, Gerardo

2010 «La revuelta de las 'ñatitas': 'Empoderamiento ritual' y ciclo de difuntos en la ciudad de La Paz (Bolivia)». Revista de Dialectología y Tradiciones Populares 65 (1): $185-214$.

Forbes, David

1870 «On the Aymara Indians of Bolivia and Peru». The Journal of the Etnological Society of London 2: 193-305.

Gelles, Paul

1986 «Sociedades hidráulicas en los Andes: algunas perspectivas desde Huarochirí». Allpanchis 18 (27): 99-147. Cuzco.

2002 Agua y poder en la sierra peruana. La historia y política cultural del riego, rito y desarrollo [2000]. Lima: Pontificia Universidad Católica del Perú.

Gerbrandy, Gerben y Paul Hoogendam

1998 Aguas y acequias. Los derechos al agua y la gestión campesina de riego en los Andes bolivianos. La Paz: Plural Editores.

Gil García, Francisco M.

2008 «A la sombra de los mallkus. Tradición oral, ritualidad y ordenamiento del paisaje en una comunidad de Nor Lípez (Potosí, Bolivia)». Revista Española de Antropología Americana 38 (1): 217-238.

s/f «Llamando lluvia desde el cerro. Ritualidad paisajística y cohesión social en una comunidad de Nor Lípez (Potosí, Bolivia)». Ponencia presentada en el 53 Congreso Internacional de Americanistas (México, julio 2009). Ms. En Espacios ceremoniales andinos, obra en preparación, coordinada por F. M. Gil García y M. Gudemos.

Greslou, F.

1990 «Visión andina y usos campesinos del agua», en Agua: visión andina y usos campesinos, F. Greslou, B. R. Diettschy, P. Geles y B. Colman, eds., pp. 9-74. La Paz: Hisbol.

Hernández PrínciPe, Rodrigo

2003 «Visita de... a Recuay» [1622], en Procesos y visitas de idolatrías. Cajatambo, siglo XVII, P. Duviols, ed., pp. 753-778. Lima: Instituto Francés de Estudios Andinos - Pontificia Universidad Católica del Perú. 
LA BARRE, Weston

1948 The Aymara Indians of the Lake Titicaca Plateau, Bolivia. Menasha: American Anthropological Association.

LimÓn Olvera, Silvia

2006 «Entidades sagradas y aguas en la antigua religión andina». Latinoamérica 43: 85-111. México.

Llanos Layme, David

2004 «Ritos para detener la lluvia en una comunidad de Charazani», en Gracias a Dios y a los achachilas. Ensayos de sociología de la religión en los Andes, A. Spedding, ed., pp. 159-184. La Paz: Plural Editores - ISEAT.

Llanque Chana, Justino

1974 Religiosidad en la agricultura aymara. Salcedo, Puno: Escuela Normal Superior San Juan Bosco.

MirAnda, Pedro

1970 Diccionario breve castellano-aymara, aymara-castellano. La Paz: Imprenta El Siglo.

Oblitas Poblete, Enrique

1978 Cultura Callawaya. La Paz: Ediciones Populares Camarlinghi.

PAREDes, M. Rigoberto

1995 Mitos, supersticiones y supervivencias populares de Bolivia [1920]. La Paz: Ediciones Isla.

PATCH, Richard W.

1971 Agricultural and the Supernatural. A Case: The Altiplano. West Coast of South America Series 18(4). Hanover: American Universities Field Staff Reports.

PeAse, Franklin

1974 «Un movimiento mesiánico en Lircay, Huancavelica (1811)». Revista del Museo Nacional 40: 221-252. Lima.

Poma de Ayala, Felipe Guamán

1987 Nueva crónica y buen gobierno [1615], 3 vols., edición de J. Murra, R. Adorno y J. L. Urioste. Crónicas de América, 29. Madrid: Historia 16.

Oliveira Cezar, Filiberto

2007 Leyendas de los indios quichuas, edición facsimilar del original impreso en Buenos Aires en 1892. Sevilla: Extramuros.

Polia Meconi, Mario

1988 Las lagunas de los encantos. Medicina tradicional andina en el Perú septentrional. Piura: Central Peruana de Servicios.

Ramos Gavilán, Alonso

1976 Historia del célebre santuario de Nuestra Señora de Copacabana y sus milagros e invención de la cruz de Carabuco [1621]. La Paz: Cámara Nacional de Comercio - Cámara Nacional de Industria.

RöSING, Ina

1996 Rituales para llamar a la lluvia [1993]. Segundo ciclo Ankara, Mundo Ankara 5, Estudios Kallawayas 6. La Paz: los Amigos del Libro. 
SIKKINK, Lynn

1997 «El poder mediador del cambio de aguas. Género y el cuerpo político condeño», en Más allá del silencio, D. Arnold, comp., pp. 94-122. La Paz: CIASE - ILCA.

Tillamnn, Hermann J.

1997 Las estrellas no mienten... Agricultura y ecología campesina andina en Jauja (Perú). Quito: Abya-Yala.

TschOpIK, Harry

1968 Magia en Chucuito. Los aymaras del Perú [1951]. México: Instituto Indigenista Interamericano.

VALDERRAma, Ricardo y Carmen Escalante

1988 Del Tata Mallku a la Mama Pacha. Riego, sociedad y ritos en los Andes peruanos. Lima: Centro de Estudios y Promoción del Desarrollo.

VALIENTE, Teresa

1986 «La fiesta del agua en Puquio». Allpanchis 18 (28): 87-97. Cuzco.

VAn Der Berg, Hans

1989 La tierra no da así no más. Los ritos agrícolas en la religión de los aymaracristianos. Amsterdam: CEDLA.

VELLARD, Jehan A.

1981 El hombre y los Andes. Buenos Aires: Ediciones Culturales Argentinas. 